\title{
Mapping Urban Networks through Inter-Firm Linkages: The Case of Listed Companies in Yangtze River Delta, China
}

\author{
Yizhen Zhang1,2, Weidong Cao ${ }^{1,2 *}$, Kun Zhang3 \\ ${ }^{1}$ School of Geography and Tourism, Anhui Normal University, Wuhu, China \\ ${ }^{2}$ Urban and Regional Planning Research Center of Anhui Normal University, Wuhu, China \\ ${ }^{3}$ College of Tourism, Huaqiao University, Quanzhou, China \\ Email: zyzdzwan@163.com, *weidongwh@163.com,kunzhang1996@163.com
}

How to cite this paper: Zhang, Y. Z., Cao, W. D., \& Zhang, K. (2020). Mapping Urban Networks through Inter-Firm Linkages: The Case of Listed Companies in Yangtze River Delta, China. Journal of Geoscience and Environment Protection, 8, 23-36. https://doi.org/10.4236/gep.2020.83003

Received: February 19, 2020

Accepted: March 17, 2020

Published: March 20, 2020

Copyright $\odot 2020$ by author(s) and Scientific Research Publishing Inc. This work is licensed under the Creative Commons Attribution International License (CC BY 4.0).

http://creativecommons.org/licenses/by/4.0/

\begin{abstract}
Recently, literature on urban network research from the perspective of firm networks has been increasing. This research mainly used data from the headquarters and branches of all 2581 listed manufacturing companies in the Yangtze River Delta from 1990 to 2017, and studied the urban network through an interlocking network model that quantifies the links between enterprises. The results showed that the spatial distribution of listed manufacturing industries in the Yangtze River Delta was relatively concentrated, and cities such as Shanghai, Nanjing, and Hangzhou were hot spots for the spatial distribution of listed manufacturing industries. However, Fuyang, Suqian, Chizhou, Lishui and other network edge cities were less distributed in manufacturing. The urban network of the Yangtze River Delta has significant hierarchical characteristics. The urban network of the Yangtze River Delta presents a multi-center network development mode with Shanghai as the center and Nanjing, Hangzhou, and Hefei as the sub-centers. Moreover, we found that the development of inter-city connections in the Yangtze River Delta was driven by network mechanisms of priority attachment and path dependence. The radiating capacity and agglomeration capacity of cities in the Yangtze River Delta have a strong polarization characteristic. The core cities such as Shanghai, Nanjing, Hangzhou, and Hefei have much higher network radiation capabilities than network aggregation capabilities. However, other non-core cities and network edge cities have weak network radiation capabilities, and mainly accept network radiation from core cities. It enriches the research of urban networks based on real inter-firm connections, and provides ideas for the wider regional study and the combination of econometric techniques and social network analysis.
\end{abstract}




\section{Keywords}

Urban Networks, Interlocking Network Model, Yangtze River Delta, China

\section{Introduction}

The rapid development of information technology and the resulting increase in inter-city linkages enables urban network an important paradigm for studying urban systems (Castells, 2001; Zhao et al., 2015). Since Beaverstock (Beaverstock et al., 1999) constructed the roster of world cities based on the produce service connections between cities, diverse kinds of inter-city linkages, including individuals, information, services, and goods, have been widely used to measure urban networks with different spatial scales (Alderson et al., 2010; Mahutga et al., 2010; Liu \& Derudder, 2013). As space carriers providing diverse kinds of productive resources, firms are key actors in the formation of urban networks.

There are currently two main streams of urban networks research. The first concerns the influencing factors of urban networks. With the further development of fragmentation of production, global production network, and global city network research, the influencing factors of urban networks are also increasing (Taylor et al., 2008; Mukhopadhyay, 2016; Csomós, 2017). Martinus uses Boschma's (2005) geographical proximity, organizational proximity, institutional proximity, social proximity, cognitive proximity as the analysis framework to verify the importance of geographical proximity to financial firm networks (Martinus \& Sigler, 2018). Yaling finds that listed medicine enterprise reshape and change urban networks by influencing city spatial structure (Yaling et al., 2018). Coe proves that cities with high-level producer service companies tend to have higher resource agglomeration and diffusion capabilities, which has a greater impact on the global commodity chain (GCC) and the World City Network (WCN) (Coe et al., 2010). Moreover, industrial, and technological gaps, as well as innovation capacity, are also considered to affect urban networks (Hoekman et al., 2010; Lai, 2018).

The second stream focuses on the research perspective of urban networks. With the liberalization and facilitation of resource flows, the connections between cities have become more frequent. As an important carrier of various "element flows", listed manufacturing companies are gradually expanding the scale and scope of urban network connections, and increasingly become the main driving force for reshaping the urban network pattern. Moreover, it has also become an important entry point for scholars to study urban networks. Feng et al. found that the productive service industry plays a vital role in the formation and development of urban networks (Feng et al., 2013). The research on the urban network based on the productive service industry can better reflect the spatial structure of the urban network. Battiston believes that the functions and effects of urban networks are different in different types of urban networks 
(Battiston et al., 2007).

Based on the literature, prevailing network analysis in the Yangtze River Delta study focuses on advanced producer service firms (Taylor et al., 2008; Cheng \& LeGates, 2018) or transnational corporations (Alderson et al., 2010), which may lead to too much concentration on a limited number of large cities and result in small cities becoming "off the map" (Robinson, 2002), especially for the Anhui Province where producer service remains less advanced. Moreover, the existing research focuses on the company's multi-location distribution, mainly using the investment data of all listed companies, and there are deficiencies in reflecting the authenticity of networks and comparing the differences across industries. To fill those gaps, this study mainly uses data from the headquarters and branches of all 2581 listed manufacturing companies in the Yangtze River Delta from 1990 to 2017, and studies the urban network through an interlocking network model that quantifies the links between enterprises. One major advantage of using data from listed manufacturing companies is that we can comprehensively and truly reflect the spatial structure of the urban network in the Yangtze River Delta. Moreover, the data can visually reflect the supply-demand relationship of manufacturing markets and avoid political bias.

The remainder of this paper is organized as follows. Section 2 presents the study area, data Sources and network construction, and research methods. Section 3 describes the spatial distribution pattern of listed manufacturing companies in the Yangtze River Delta. Moreover, the spatial pattern of the urban network is further explored from the node and hierarchical characteristics. Section 4 summarizes the conclusions and future research opportunities.

\section{Data and Methods}

\subsection{Study Area}

As shown in Figure 1, the Yangtze River Delta urban agglomeration is composed of four province-level areas, including Shanghai (municipality), Jiangsu Province, Zhejiang Province, and parts of Anhui Province. Among 40 other cities, there are three provincial capitals (Nanjing of Jiangsu Province, Hangzhou of Zhejiang Province, and Hefei of Anhui Province), a vice-provincial city (Ningbo of Zhejiang Province), and 36 prefecture-level cities. In 2018, the population in Yangtze River Delta accounted for $10.71 \%$ of China's total population, $3.7 \%$ of the nation's land area, and over $20.1 \%$ of its gross domestic product (GDP). The Yangtze River Delta region features the largest urban agglomeration in China with well-developed transportation infrastructure and economic connection (Liang et al., 2019).

\subsection{Data Sources}

The CSMAR database is currently the largest and most accurate financial and economic database in China. It consists of 8 series including stocks, listed companies, economy, industry, high-frequency data and personalized data services. 


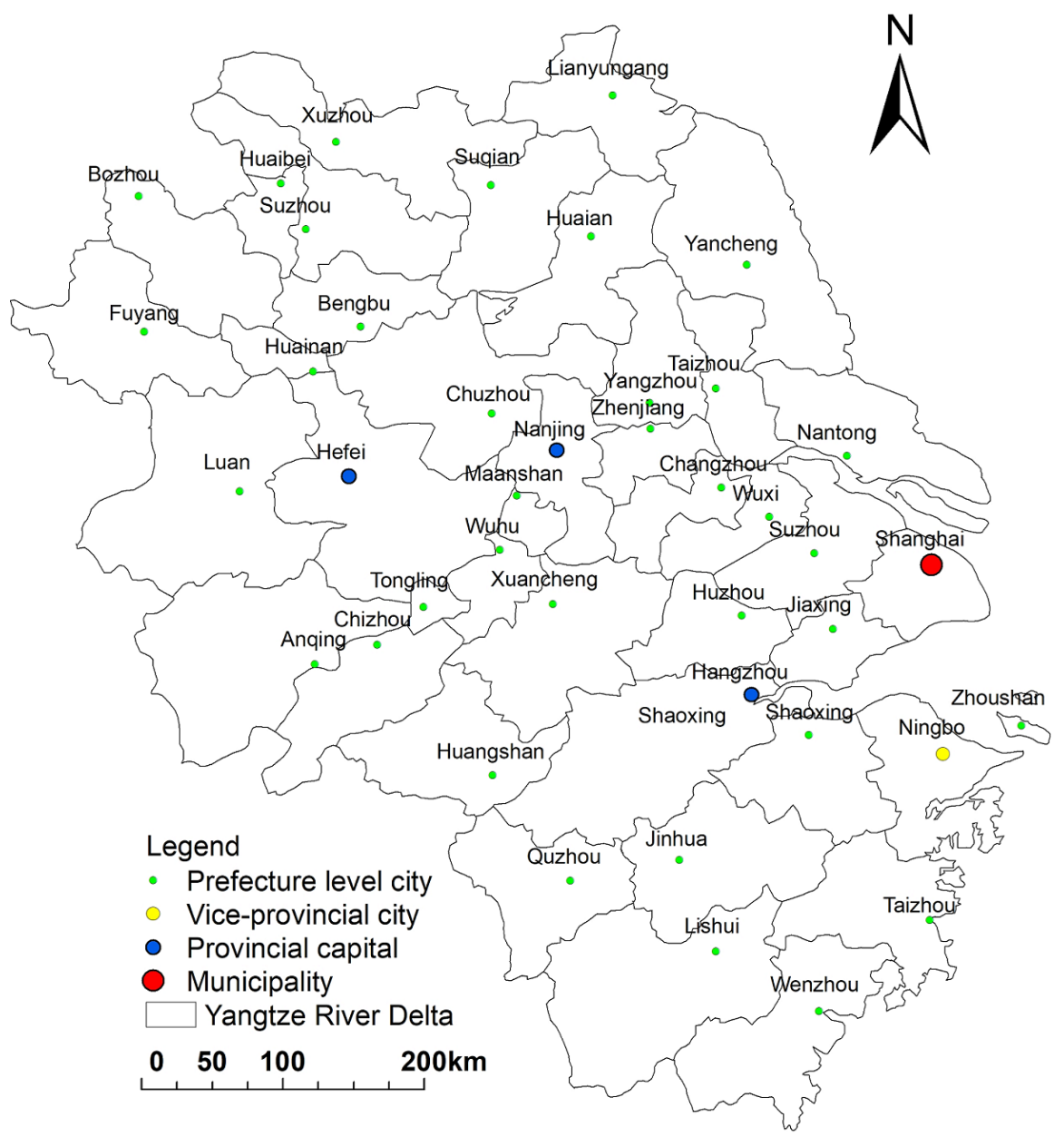

Figure 1. Location map of the Yangtze River delta.

We collected the headquarters and its branches of listed manufacturing companies through the following conditions. 1) There is at least one branch office and it belongs to a different city from the head office. 2) The head office and branches must have clear registration time, registered address, existence status and other attribute information. 3) The data of financial companies whose head offices and branches have registered counties, county-level cities, and districts are all merged into the prefecture-level cities. We have collected 137 manufacturing enterprise headquarters in Shanghai, 329 branches, 284 manufacturing enterprise headquarters in Jiangsu province, 785 branches, 335 manufacturing enterprise headquarters in Zhejiang province, 1190 branches, 68 manufacturing enterprise headquarters in Anhui province and 277 branches, as shown in Figure 2.

\subsection{Research Methods}

\subsubsection{Kernel Density Analysis}

Kernel density analysis is used to calculate the unit density of point and line element measurements within a specified neighborhood. It can intuitively reflect the distribution of discrete measurements in a continuous area (Nagler, 2017). 


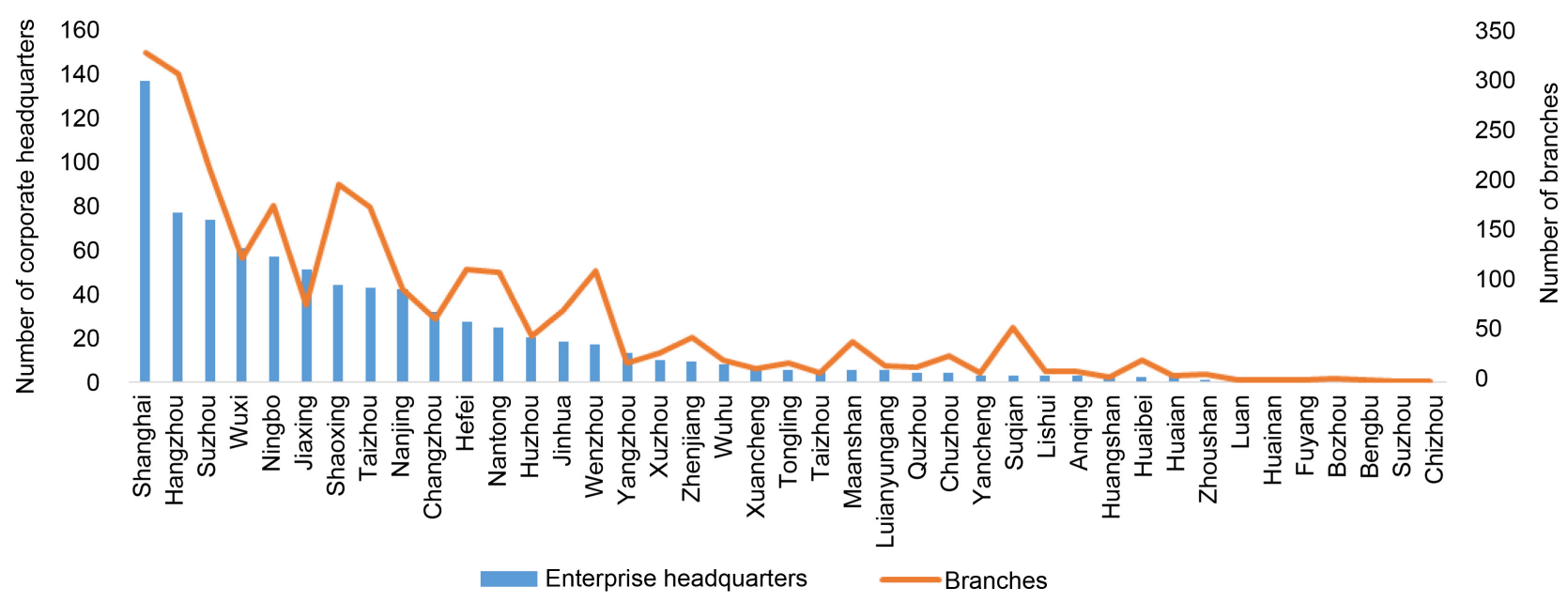

Figure 2. Number of corporate headquarters and branches.

In this study, the kernel density analysis is used to represent the spatial distribution density of manufacturing enterprises in the Yangtze River Delta. The formula is as follows:

$$
D=\frac{3\left(1-\text { scale }^{2}\right)^{2}}{\pi r^{2}}
$$

Among them, $r$ is the search radius, and scale is the ratio of the distance from the grid center point to the point and line object to the search radius. For a point object, the volume of the space enclosed by the kernel density surface and the lower plane is approximately the measured value at this point. For a line object, the volume of the space enclosed by the kernel density surface and the lower plane is approximately the product of the measured value of this line and the length of the line. Where the neighborhoods of points or lines overlap, their density values are also added. The density of each output raster is the sum of all kernel surface values superimposed on the raster. The unit of the result raster value is the inverse of the square of the unit of the original data set, that is, if the unit of the original data set is meters, the unit of the result raster value is per square meter.

\subsubsection{Interlocking Network Model}

To accurately describe the network connections formed between the sub-agency, agency, local branch company, regional branch company and enterprise headquarters. This study consulted experts and professors in the manufacturing industry, and combined with relevant references, worked out a valuation scheme for multi-level enterprise connection strength (Jun et al., 2011). Based on this, a modified network linkage model is proposed. The formula is as follows:

$$
R_{a b}=\sum_{j=1}^{n}\left(3 C_{z k}+2 C_{s k}+C_{h k}+C_{l k}\right)
$$

In the formula, $R_{a b}$ represents the one-way connection strength between city $\mathrm{i}$ and city $\mathrm{j}$. The larger $R_{a b}$ means the stronger the one-way connection between 
city a and city b; $n$ represents the number of head offices owned by city a. $C_{Z K}$, $C_{S K}, C_{H K}$ and $C_{L K}$ respectively represent the number of head offices located in city a, but his sub-agencies and agencies, local branch company and regional branch company in city b.

\subsubsection{Degree Centrality}

Degree centrality is a direct measure of the centrality of a node. The greater the degree centrality of a node, the higher the power and status of the node, and the more central it is in the network (Pan et al., 2017). The formula is as follows:

$$
N_{a}=\sum_{i=1}^{40} \sum_{j=1}^{n} V_{a, j} V_{b, j}(i \neq j)
$$

In the formula, $N_{a}$ represents the degree centrality of city a, $V_{a, j}$ represents the weight of enterprise $j$ in city a, $V_{b, j}$ represents the weight of enterprise $j$ in city b, $i$ represents the number of cities in the region, and $j$ represents the number of enterprises in the region.

\section{Results}

\subsection{Spatial Distribution Characteristics of Listed Manufacturing Companies in the Yangtze River Delta}

According to Baidu coordinate pick-up system, the longitude and latitude coordinates of the headquarters of all listed manufacturing enterprises in Yangtze River Delta are obtained. Moreover, spatial labelings of latitude and longitude and kernel density analysis were performed in Arcgis 10.2. The results are shown in Figure 3.

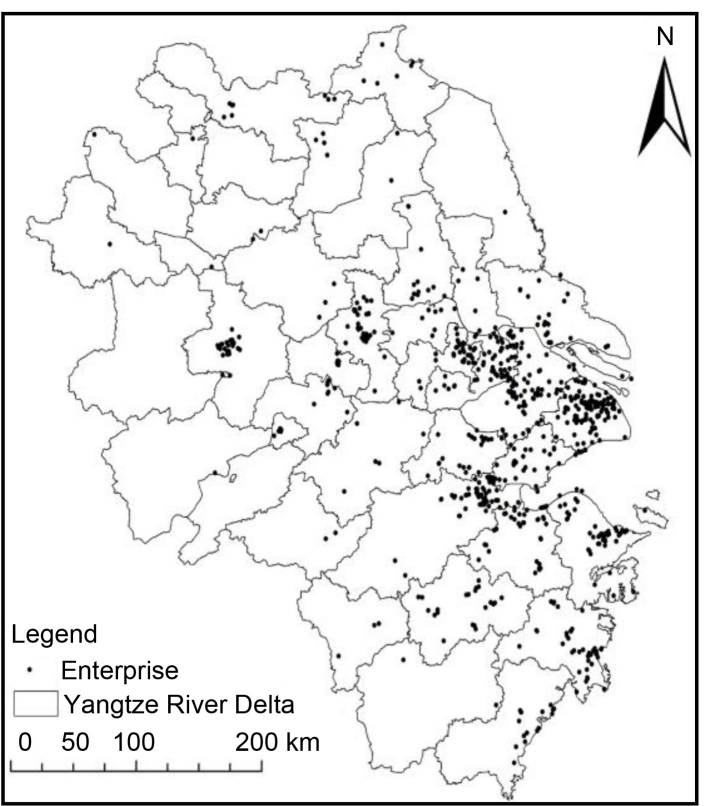

(a)

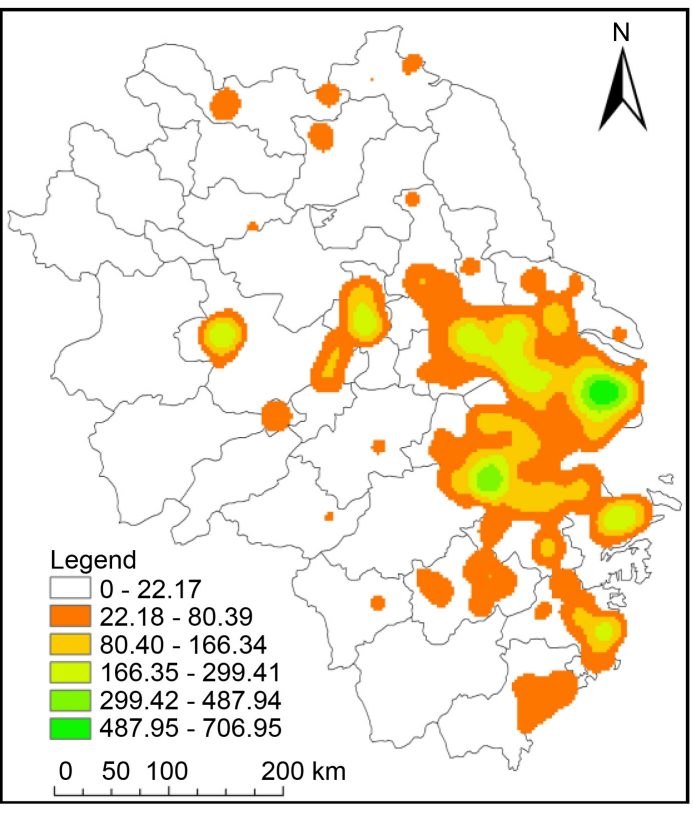

(b)

Figure 3. Spatial distribution and kernel density analysis of manufacturing industry. (a) Location of listed companies; (b) Kernel density analysis. 
From a regional perspective, Shanghai ranks behind Jiangsu and Zhejiang in the number of listed manufacturing enterprises. However, the administrative area of Shanghai is also significantly smaller than that of Jiangsu and Zhejiang provinces, so the spatial distribution of listed manufacturing enterprises in Shanghai is relatively dense, and the number of listed manufacturing enterprises registered per unit area is relatively large. Moreover, the Kernel Density value of Shanghai's manufacturing industry is the highest, and its polarization development trend is more significant. It can be observed that distance attenuation is a key factor restricting the spatial distribution of listed companies in Shanghai. It is worth mentioning that the spatial distribution of listed manufacturing companies in Fengxian and Chongming district of Shanghai is relatively small, but their manufacturing space distribution is closely linked with Suzhou, Wuxi and Changzhou.

The spatial distribution of listed manufacturing enterprises in Jiangsu Province has strong spatial heterogeneity, forming two major agglomeration centers in Nanjing and Suzhou. However, the spatial distribution of listed manufacturing companies in northern and central Jiangsu is relatively small and scattered. Moreover, although Nanjing has a large number of listed manufacturing companies, its surrounding cities have fewer listed manufacturing companies. However, the trend of interactive development of Suzhou-Wuxi-Changzhou is relatively obvious, forming a relatively close manufacturing development system, and working with Shanghai to build a world-class advanced manufacturing development cluster. Moreover, in central and northern Jiangsu and other places, the manufacturing industry is scattered, the industrial chain is short, and the industrial concentration is relatively low. In the future, it is necessary to further rely on existing resources, extend the industrial chain by industrial agglomeration, and adjust the industrial structure of the manufacturing industry.

Zhejiang Province has a large number of listed manufacturing enterprises, and its average Kernel Density value is relatively large. Moreover, a spatial development pattern of "one axis, three centers" with "Huzhou, Jiaxing, Shaoxing" as the manufacturing development axis and Hangzhou, Ningbo, and Taizhou as the manufacturing development centers has been formed. As the capital city of Zhejiang Province, Hangzhou can better play its pivotal role and promote complementary and coordinated development of neighboring cities. Ningbo and Taizhou, as two other manufacturing development centers in Zhejiang Province, have also gathered more listed manufacturing companies. Together with Hangzhou, they form a "one-axis, three-center" listed manufacturing company spatial distribution pattern, and jointly promote the coordinated development of manufacturing enterprises in Zhejiang Province.

The number of manufacturing enterprises in Anhui Province is relatively small and the distribution is relatively concentrated. Hefei has gathered a large number of listed manufacturing enterprises in the province, and the development trend of single-center agglomeration is more significant. It is worth men- 
tioning that the development situation of the Wuhu-Maanshan Manufacturing Development Group is more prominent. In the future, it is necessary to strengthen the "Shanghai, Jiangsu and Zhejiang" transfer of manufacturing in Anhui, and promote the construction of dual-core cities in Hefei and Wuhu. Meanwhile, accelerate the full integration of Anhui's manufacturing industry into the Yangtze River Delta, and create a new pattern of integrated and coordinated development of the Yangtze River Delta manufacturing industry.

\subsection{Network Characteristics of Listed Manufacturing Companies in the Yangtze River Delta}

\subsubsection{Urban Network Hierarchy Features Are Obvious, and the Core Skeleton Is Radial with Shanghai as the Center}

The urban network is constructed through the interlocking network model, combined with Arcgis 10.2 spatial analysis and natural fracture method, the urban network of the Yangtze River Delta is divided into 5 levels from large to small. The results are shown in Figure 4.

The first-level and second-level connections of the urban network in the Yangtze River Delta (209-784) are mainly radial to the southeast of Zhejiang and southern Jiangsu with Shanghai as the center. Among them, Shanghai-Suzhou (784), Shanghai-Shaoxing (764), Shanghai-Hangzhou (756), Shanghai-Wenzhou (648), Shanghai-Ningbo (632) are the five city pairs with the strongest connection, which form the core skeleton of the urban network in the Yangtze River Delta. There are 36 city pairs with third-level contacts (100-208), which is significantly more than the number of city pairs with first-level and second-level contacts, and the scope of contacts has also expanded. However, it is mainly based on the proximity and directional connection between cities in Jiangsu and Zhejiang provinces or the leaping connection between cities in Jiangsu and Zhejiang provinces and Shanghai. However, most cities in Anhui have not completely broken the boundaries of time and space, and have no connection with other cities in the region. There are 279 city pairs in the fourth and fifth level (4-99), which is 7.75 times more than the number of city pairs in the third level. Moreover, Fuyang, Huangshan, Chizhou, Huainan, Suqian and other network edge cities have gradually broken through administrative barriers to establish links with Shanghai and Nanjing. However, the strength of the network connection is weak and the degree of network integration is low. In the future, the network rights and status of cities on the edge of the network will need to be further strengthened to promote the development of cities in the Yangtze River Delta to a higher quality.

\subsubsection{Strong Spatial Heterogeneity in Urban Network Radiation and Agglomeration Capabilities}

The weighted in-degree and weighted out-degree represent the radiation and aggregation capacity of the urban network. Cities with large weighted in-degree and weighted out-degree often have higher rights and status, and have greater control over the resources of cities on the edge of the network. Combining 


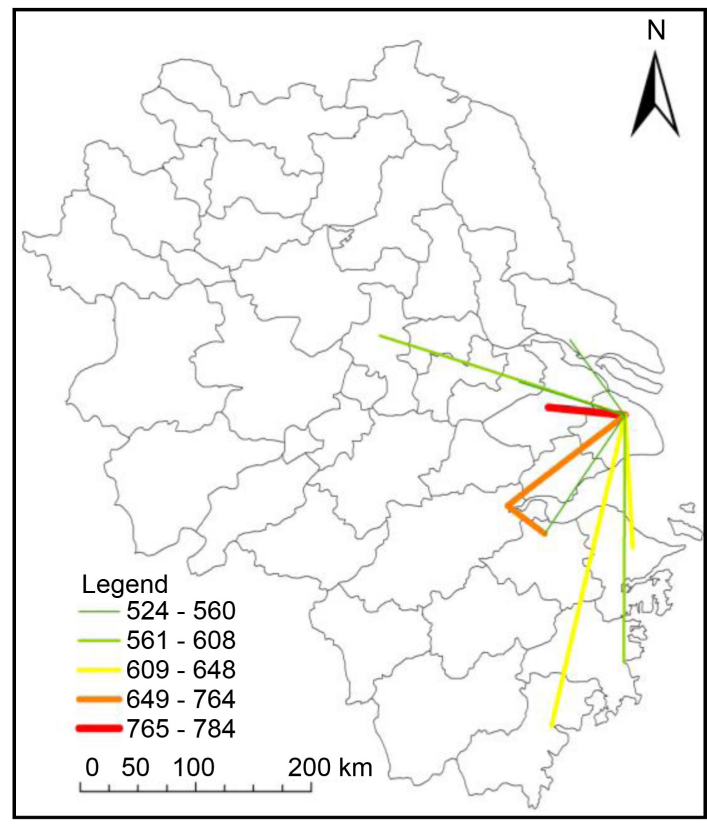

(a)

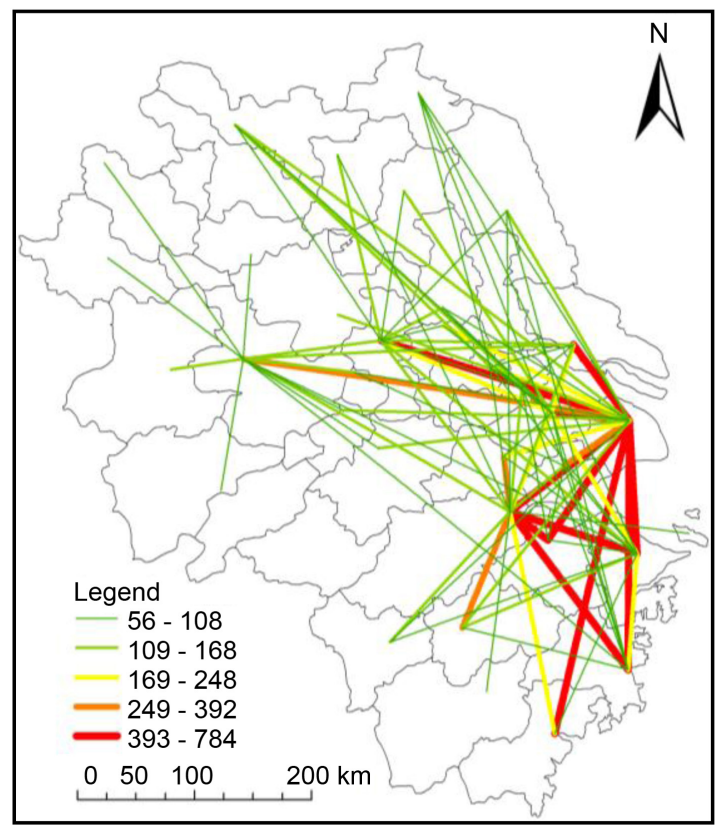

(c)

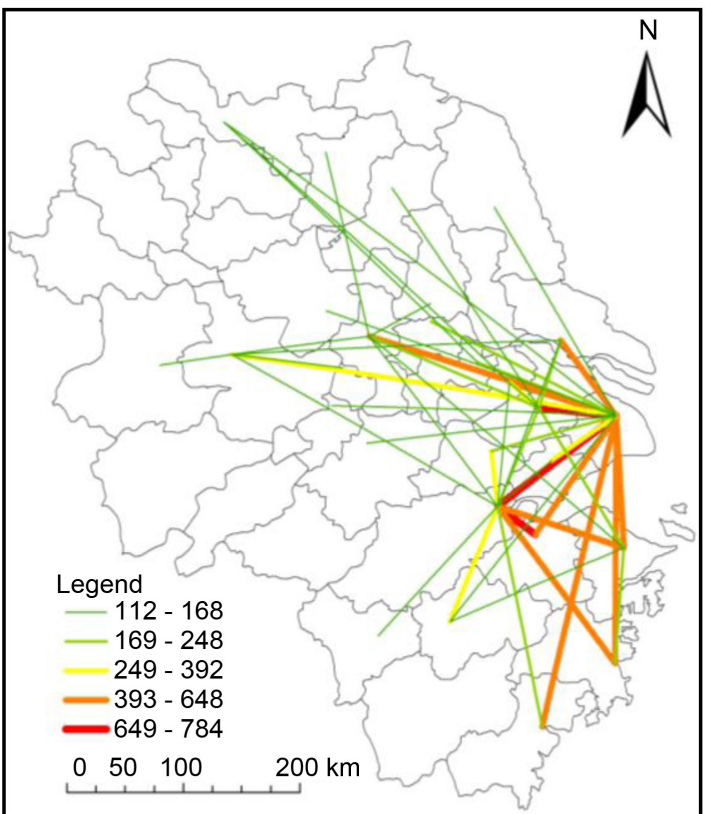

(b)

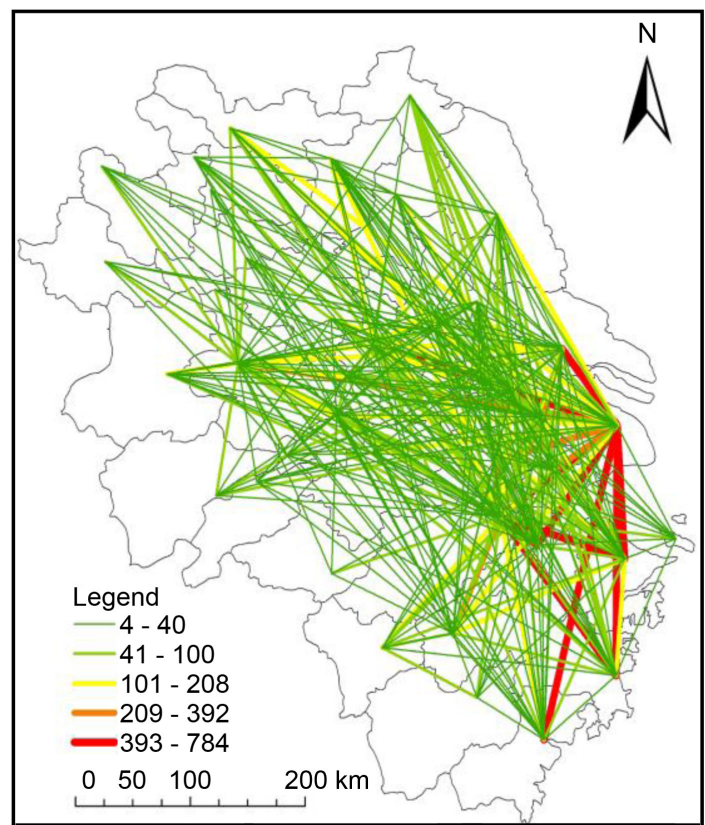

(d)

Figure 4. Network of listed manufacturing companies in the Yangtze River delta. (a) Top 10 inter-city connection. (b) Top 50 inter-city connections. (c) Top 100 inter-city connections. (d) All inter-city connections.

Gephi social network analysis tools and social network analysis methods, this paper explores the radiation and agglomeration capabilities of the urban network in the Yangtze River Delta from the perspective of weighted in-degree and weighted out-degree. The results are shown in Figure 5.

From the perspective of radiation capacity: The total radiation in Shanghai is 3488 , and the radiation range is as wide as 33 cities. Among them, the radiation to Suzhou (668), Nanjing (480), Hangzhou (292), Hefei (256), Nantong (220) is 


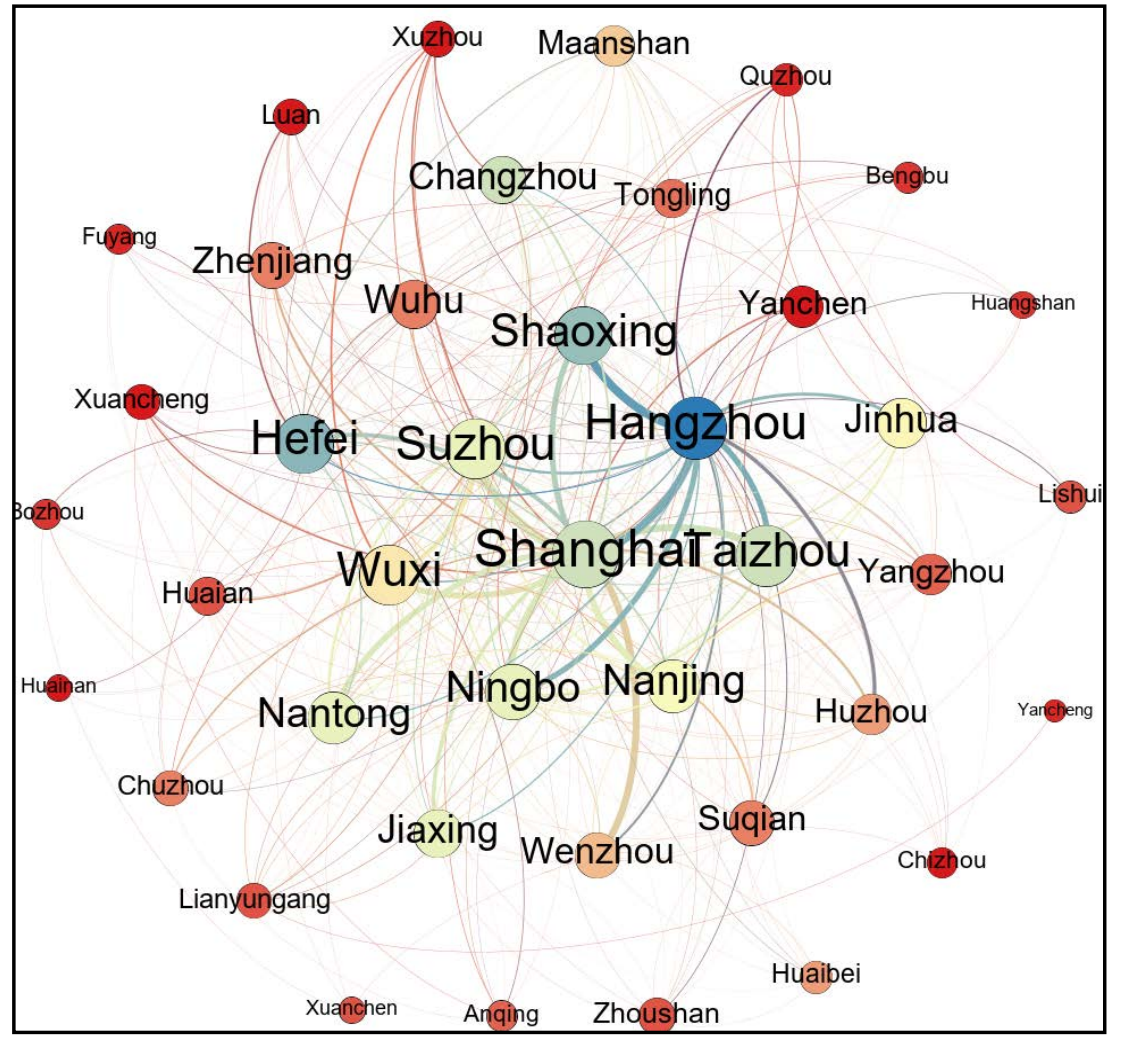

(a)

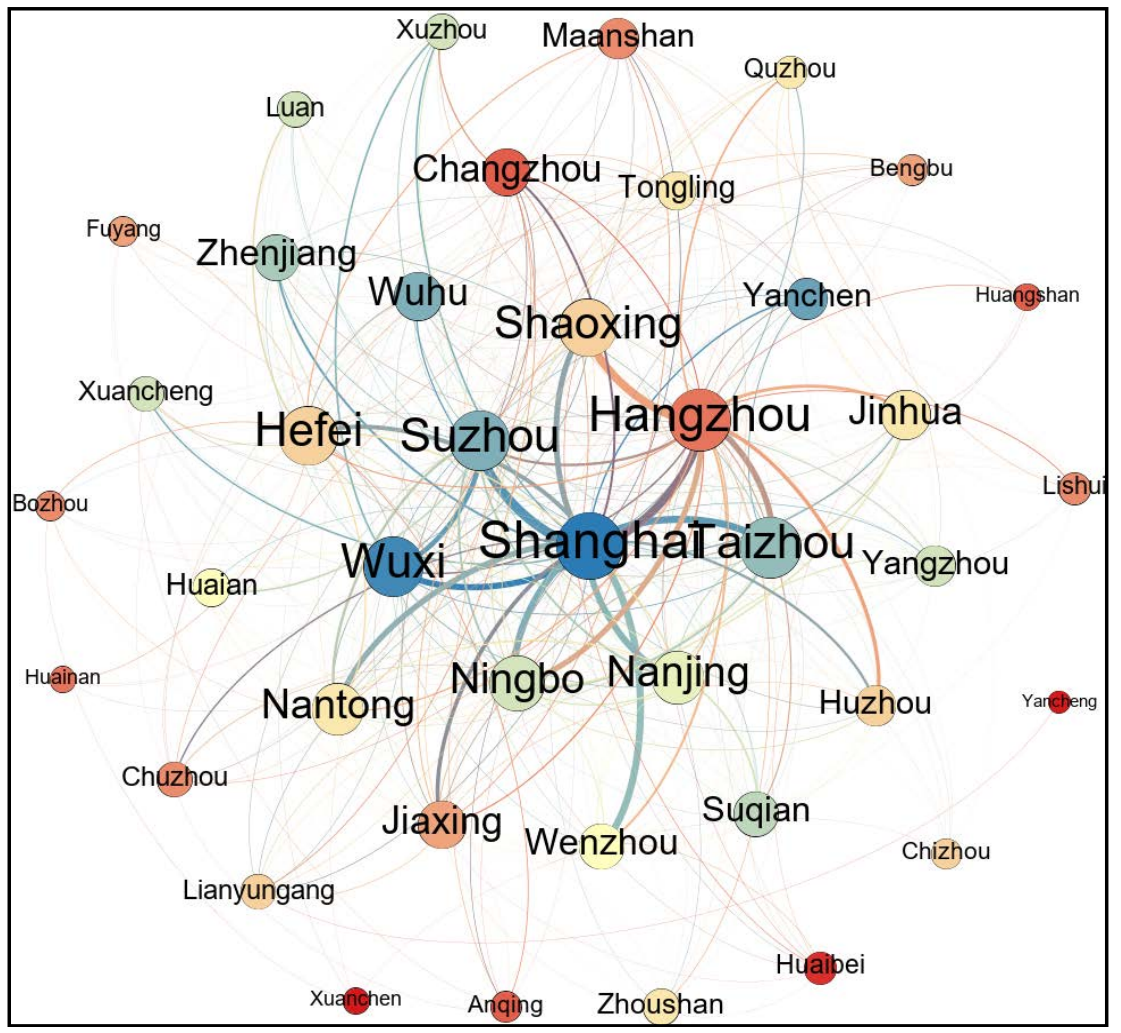

(b)

Figure 5. The weighted in-degree and weighted out-degree of the urban network in the Yangtze River delta. 
relatively large, and to Shaoxing (24), Taizhou (24), Huainan (12), Maanshan (12) and Chizhou (8) is relatively small. Moreover, only cities on the edge of the network such as Bozhou and Huangshan in Anhui did not receive radiation from Shanghai. It shows that Shanghai has strong advantages in resource allocation, and has greater network control capabilities in cities such as Suzhou, Nanjing, Hangzhou, and Hefei. The top five cities in Jiangsu's external radiation intensity are Suzhou (1792), Wuxi (1424), Nantong (976), Nanjing (840), and Changzhou (592). Among them, Suzhou, Wuxi, Nantong, and Nanjing had the largest radiation to Shanghai, with radiation intensity of $636,376,328$, and 112 , respectively. It shows that cities such as Suzhou, Nanjing, and Nantong, while receiving Shanghai's network radiation, also radiate Shanghai in turn. The top five cities in Zhejiang Province's external radiation intensity were Hangzhou (2972), Shaoxing (1940), Taizhou (1732), Ningbo (1660) and Wenzhou (1112). Among them, the cities with the largest external radiation in Hangzhou, Shaoxing, Taizhou, and Ningbo are Shanghai, with radiation intensity of 464, 556, 576, 512, and 580, respectively. Moreover, Hangzhou produces different radiation intensities to other 10 cities in Zhejiang Province, and forms the radiation axis of Hangzhou-Ningbo, Hangzhou-Huzhou, Hangzhou-Shaoxing. It shows that Hangzhou, as the capital of Zhejiang Province, is closely connected with other cities in the province. The overall external radiation intensity of cities in Anhui Province is relatively weak. The overall external radiation intensity of each city in Anhui Province is relatively weak. The top five cities for external radiation intensity are Hefei (1088), Maanshan (388), Luzhou (248), Wuhu (196), and Tongling (196). Moreover, only Hefei has the ability to generate radiation in cities in Zhejiang and Jiangsu provinces and Shanghai. However, the external radiation range of other cities in Anhui Province is mainly concentrated in cities within the province, and the radiation intensity is weak. Among them, southern and northern Anhui cities, such as Chizhou and Suzhou, have not yet had radiation capabilities.

From the perspective of agglomeration capabilities: by 2017, Shanghai had received radiation from 35 cities in the Yangtze River Delta, resulting in a total concentration of 5840. It can be observed that Shanghai has a strong ability to gather resources, and has a more significant "siphon effect" on talents and funds in other cities in the Yangtze River Delta. The top five cities in Jiangsu's resource agglomeration capacity are Suzhou (1940), Nanjing (1576), Wuxi (928), Nantong (692), and Xuzhou (492). Moreover, most other cities in Jiangsu Province have also formed strong resource collection capabilities. There are significant differences in the resource gathering capacity of cities in Zhejiang Province. The top five cities for agglomeration capacity are Hangzhou (2380), Ningbo (1240), Jiaxing (556), Huzhou (528), and Jinhua (464). Among them, Hangzhou with the strongest agglomeration capacity is 23.8 times higher than Lishui with the smallest agglomeration capacity. It is worth mentioning that cities with strong resource radiation capabilities, such as Shaoxing, Taizhou, and Wenzhou, have 
not formed high resource agglomeration capabilities, which has also made Zhejiang a depression with "net output" of resources. Moreover, the overall resource agglomeration capacity of Anhui Province is weak and the level of agglomeration is low. The top five cities for resource agglomeration capacity are Hefei (1140), Wuhu (476), Xuancheng (364), Luan (348), and Maanshan (236). However, unlike the radiation capability, although Chizhou, Suzhou and other peripheral cities have not formed a radiation capability, they have formed a strong network aggregation capability. It shows that Chizhou, Suzhou and other network edge cities are gradually improving their network status and actively integrating into the integrated development of the Yangtze River Delta.

\section{Conclusion and Discussion}

\subsection{Conclusions}

This study mainly uses data from the headquarters and branches of all 2581 listed manufacturing companies in the Yangtze River Delta from 1990 to 2017, and studies the urban network through an interlocking network model that quantifies the links between enterprises. Moreover, the characteristics of urban network in the Yangtze River Delta are explored in combination with Kernel Density analysis and social network analysis models.

The results show that the spatial distribution of listed manufacturing industries in the Yangtze River Delta is relatively concentrated. Cities such as Shanghai, Nanjing, and Hangzhou are the major gathering places for listing and manufacturing in the Yangtze River Delta. However, the number of manufacturing clusters in edge cities such as Fuyang, Suqian and Lishui is relatively small. The urban network of the Yangtze River Delta presents a multi-center network development mode with Shanghai as the center and Nanjing, Hangzhou, and Hefei as the sub-centers. Moreover, we found that the development of inter-city connections in the Yangtze River Delta is driven by network mechanisms of priority attachment, hierarchy, and path dependence. Furthermore, the radiating capacity and agglomeration capacity of the cities in the Yangtze River Delta have strong polarization characteristics. The core cities such as Shanghai, Nanjing, Hefei, and Hangzhou have much higher radiating capacity than the agglomeration capacity. However, other non-core cities and network edge cities have weak network radiation capabilities, and mainly accept network radiation from core cities.

\subsection{Discussion}

There are a number of limitations in our paper that needs to be taken up by future research. One limitation relates to a concern about the representativeness of the intra-enterprise data. Although our data source is widely recognized as a valuable repository appropriate for detailed geographical research, the data only provide information on the headquarters-branch relationship. Some recent studies suggested that inter-enterprise linkages are essential contributors to the 
formation of intercity connections. Moreover, the next step is to determine the main drivers behind the evolution of the urban network in the Yangtze River Delta we presented.

\section{Conflicts of Interest}

The author declares no conflicts of interest regarding the publication of this paper.

\section{References}

Alderson, A. S., Beckfield, J., \& Sprague-Jones, J. (2010). Intercity Relations and Globalisation: The Evolution of the Global Urban Hierarchy, 1981-2007. Urban Studies, 47, 1899-1923. https://doi.org/10.1177/0042098010372679

Battiston, S., Rodrigues, J. F., \& Zeytinoglu, H. (2007). The Network of Inter-Regional Direct Investment Stocksacross Europe. Advances in Complex Systems, 10, 29-51. https://doi.org/10.1142/S0219525907000933

Beaverstock, J. V., Smith, R. G., \& Taylor, P. J. (1999). A Roster of World Cities. Cities, 16, 445-458. https://doi.org/10.1016/S0264-2751(99)00042-6

Boschma, R. A. (2005). Proximity and Innovation: A Critical Assessment. Regional Studies, 39, 61-74.

Castells, M. (2001). The Rise of Network Society (2nd ed.). Oxford, UK: Blackwell.

Cheng, Y., \& LeGates, R. (2018). China’s Hybrid Global City Region Pathway: Evidence from the Yangtze River Delta. Cities, 77, 81-91.

https://doi.org/10.1016/j.cities.2018.01.015

Coe, N., Dicken, P., Hess, M., \& Yeung, H. (2010). Making Connections: Global Production Networks and World City Networks. Global Networks, 10, 138-149. https://doi.org/10.1111/j.1471-0374.2010.00278.x

Csomós, G. (2017). Cities as Command and Control Centres of the World Economy: An Empirical Analysis, 2006-2015. Bulletin of Geography. Socio-Economic Series, 38, 7-26. https://doi.org/10.1515/bog-2017-0031

Feng, Z., Xia, W., Jun, Y., \& Min, Z. (2013). An Empirical Study on Chinese City Network Pattern Based on Producer Services. Chinese Geographical Science, 23, 274-285. https://doi.org/10.1007/s11769-013-0595-8

Hoekman, J., Frenken, K., \& Tijssen, R. J. W. (2010). Research Collaboration at a Distance: Changing Spatial Patterns of Scientific Collaboration within Europe. Research Policy, 39, 662-673. https://doi.org/10.1016/i.respol.2010.01.012

Jun, Y., Feng, Z., \& Wang, C.-H. (2011). China’s City Network Pattern: An Empirical Analysis Based on Financial Enterprises Layout. Economic Geography, 31, 754-759. (In Chinese)

Lai, K. P. (2018). Agency, Power, and State-Firm Relations in Global Financial Networks. Dialogues in Human Geography, 8, 285-288. https://doi.org/10.1177/2043820618797463

Liang, S., Cao, Y., Wu, W., Gao, J., Liu, W., \& Zhang, W. (2019). International Freight Forwarding Services Network in the Yangtze River Delta, 2005-2015: Pattern sand Mechanisms. Chinese Geographical Science, 29, 112-126.

https://doi.org/10.1007/s11769-019-1018-2

Liu, X., \& Derudder, B. (2013). Analyzing Urban Networks through the Lens of Corporate Networks: A Critical Review. Cities, 31, 430-437. 
https://doi.org/10.1016/j.cities.2012.07.009

Mahutga, M. C., Ma, X., Smith, D. A., \& Timberlake, M. (2010). Economic Globalisation and the Structure of the World City System: The Case of Airline Passenger Data. Urban Studies, 47, 1925-1947. https://doi.org/10.1177/0042098010372684

Martinus, K., \& Sigler, T. J. (2018). Global City Clusters: Theorizing Spatial and Non-Spatial Proximity in Inter-Urban Firm Networks. Regional Studies, 52, 1041-1052. https://doi.org/10.1080/00343404.2017.1314457

Mukhopadhyay, C. (2016). Megaregions: Globalization's New Urban Form? European Planning Studies, 24, 420-422. https://doi.org/10.1080/09654313.2015.1087178

Nagler, T. (2017). Asymptotic Analysis of the Continuous Convolution Kernel Density Estimator. Mathematical Methods of Statistics, 27, 32-46. https://doi.org/10.3103/S1066530718010027

Pan, F., Bi, W., Lenzer, J., \& Zhao, S. (2017). Mapping Urban Networks through Inter-Firm Service Relationships: The Case of China. Urban Studies, 54, 3639-3654. https://doi.org/10.1177/0042098016685511

Robinson, J. (2002). Global and World Cities: A View from off the Map. International Journal of Urban and Regional Research, 26, 531-554. https://doi.org/10.1111/1468-2427.00397

Taylor, P. J., Evans, D. M., \& Pain, K. (2008). Application of the Interlocking Network Model Tomega-City-Regions: Measuring Polycentric City within and beyond City-Regions. Regional Studies, 42, 1079-1093. https://doi.org/10.1080/00343400701874214

Yaling, Y. E., Bofei, Y. A., Ziyun, H. E., Beini, Z. E., Fenghua, P. A., \& Cheng, F. A. (2018). Spatial Structure of Urban Network Based on Chinese A-Share Listed Medicine Enterprise Network. Progress in Geography, 37, 1096-1105. (In Chinese)

https://doi.org/10.18306/dlkxjz.2018.08.009

Zhao, M., Wu, K., Liu, X., \& Ben, D. (2015). A Novel Method for Approximating Intercity Networks: An Empirical Comparison for Validating the City Networks in Two Chinese City-Regions. Journal of Geographical Sciences, 25, 337-354. (In Chinese) https://doi.org/10.1007/s11442-015-1172-0 